First publ. in: Animal Behaviour ; 82 (2011), 1. - pp. 77-83

DOI: 10.1016/j.anbehav.2011.03.026

\title{
Work or sleep? Honeybee foragers opportunistically nap during the day when forage is not available
}

\author{
Barrett A. Klein ${ }^{a, *}$, Thomas D. Seeley ${ }^{b}$

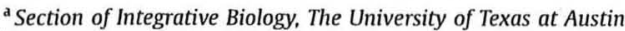 \\ ${ }^{\mathrm{b}}$ Department of Neurobiology and Behavior, Cornell University
}

\section{A R T I C L E I N F O}

\section{Keywords:}

Apis mellifera

foraging

honeybee

nap

plasticity

shift work

sleep
Shifts in work schedules test humans' capacity to be flexible in the timing of both work and sleep. Honeybee, Apis mellifera, foragers also shift their work schedules, but how flexible they are in the timing of sleep as they shift the timing of work is unknown, despite the importance of colony-level plasticity in the face of a changing environment. We hypothesized that sleep schedules of foragers are not fixed and instead vary depending on the time when food is available. We trained bees to visit a food source made available for several hours in the early morning (AM) or several hours in the late afternoon (PM), then monitored their sleep behaviour for $24 \mathrm{~h}$ after training, specifically comparing their sleep during the AM and PM periods previously designated as training periods. Following AM training, honeybee foragers slept more during the afternoon than during the morning, but following PM training, the same bees 'slept in' the next morning, and so slept more in the morning than in the afternoon. Although foragers did not change the total amount of time devoted to each of their behaviours (including sleep), the timing of their sleep did change. Thus, plasticity in timing of foraging was matched by plasticity in timing of sleep. The apparent correlation between the timing patterns of foraging and sleeping demonstrates temporal plasticity of sleep under ecologically realistic conditions in an invertebrate. Testing how shift work affects the health and performance of honeybees may shed light on the role of sleep in a nonhuman social animal.
Humans often institute 'shift work', an employment practise that attempts to make full use of each day's time by requiring employees to accommodate shifting work schedules. Extreme changes in circadian cycles of work/sleep can cause varied health and performance problems (reviewed by Rajaratnam \& Arendt 2001; Garbarino et al. 2002; Arendt 2010) ranging from cancers and gastrointestinal dysfunction (Costa 1996) to degraded ability to detect simulated threats (weapons) as a luggage screener (Basner et al. 2008). Extreme shifting of work schedules requires shifting of sleep schedules, whereupon planned napping can aid in performance (Smith-Coggins et al. 2006), even under stable daytime work schedules (reviewed by Dhand \& Sohal 2006). The ability to respond flexibly to changes in work schedules by changing sleep schedules exists in humans, but is not well established in nonhuman animals under relatively normal working conditions (i.e. when not forcibly sleep deprived). To probe the evolutionary breadth of sleep flexibility, we need to understand what defines sleep and we need to test the ability of nonhuman

* Correspondence and present address: B. A. Klein, Department of Neurobiology \& Behavior, Cornell University, Ithaca, NY 14853, U.S.A.

E-mail address: barrett@pupating.org (B.A. Klein). animals to accommodate changes in the timing of wake-state activities with changes in the timing of sleep. Our aim was to test whether honeybee foragers show flexibility in timing of sleep following a change in timing of work.

Defining sleep behaviourally requires identifying a suite of behavioural traits indicative of sleep. A sleeping organism tends to be quiescent, shows a posture that is stereotypical or species specific, and is in a state that is easily reversed, but only with increased external stimulation (Piéron 1913; Flanigan et al. 1973). According to Tobler (1985), a sleeping organism also experiences compensatory sleep after suffering a sleep deficit. Sleep has been defined behaviourally by meeting the above diagnostic criteria in honeybees, Apis mellifera (Kaiser 1988), the fruit fly Drosophila (Sophophora) melanogaster (Hendricks et al. 2000; Shaw et al. 2000) and other insects (Tobler 1983; Tobler \& Neuner-Jehle 1992; Klein 2003). One feature that invariably accompanies the other sleep indicators in honeybees is discontinuous ventilation (Sauer et al. 2003). Sleeping bees ventilate their bodies discontinuously; they perform several dorsoventral pulses of the abdomen followed by extended pauses of immobility (Kaiser et al. 1996; Kleinhenz et al. 2003; Sauer et al. 2003). Discontinuous ventilation is a particularly useful indicator of sleep in bees because it can 
be assayed when bees are either inside or outside of comb cells. Sometimes bees sleep for extended periods with their antennae immobile, and during this time their thresholds of response to disturbance are elevated. Bees showing these behavioural traits have been described as being in a state of deep sleep (Kaiser 1988).

If sleep is important for honeybees, as is suggested by the results of sleep deprivation studies (Sauer et al. 2004; Hussaini et al. 2009; Klein et al. 2010), then the diurnally active foragers in a colony should sleep at night. Like humans, foragers do so (Kaiser 1988; Sauer et al. 2003; Eban-Rothschild \& Bloch 2008; Klein et al. 2008). Foragers have strong circadian tendencies to be inactive at night (Lindauer 1952; Spangler 1972; Kaiser \& Steiner-Kaiser 1983; Moore et al. 1998; Toma et al. 2000; Moore 2001), but they also can be inactive during the day. Daytime quiescence by foragers has been reported by Körner (1939), von Frisch $(1940,1967)$, Lindauer (1952) and Moore et al. (1989), but this quiescence was not shown to be sleep. Is this daytime quiescence in foragers opportunistic napping?

Foraging need not be a day-long pursuit, and is often driven by a stunningly precise anticipatory Zeitgedächtnis, or time sense (Beling 1929; Koltermann 1971; Moore et al. 1989). Unlike their younger siblings (Moore et al. 1998), foragers can perform tasks in a manner that resembles shift work, leaving time in the day available for rest. Honeybees are highly flexible in the timing of foraging (Beling 1929; Wahl 1932, 1933; Moore \& Rankin 1983; Moore et al. 1989), and although this temporal flexibility in foraging is well understood to depend on changes in resource supply and demand (reviewed in von Frisch 1967, pp. 253-255), nothing is known about how foragers change the timing of their sleep in response to changes in the timing of their foraging.

Given honeybees' temporal flexibility in foraging and given their need for sleep, we hypothesized that honeybee foragers can adjust the timing of their sleep in relation to the timing of their work. Based on this hypothesis, we predicted that foragers trained to exploit an early morning resource would show an earlier onset of sleep than foragers trained to exploit a late afternoon resource. Likewise, we predicted that foragers trained to exploit a resource late in the afternoon (with insufficient daytime after foraging to experience earlier sleep onset) would rouse themselves later in the morning (i.e. would 'sleep in') than would foragers trained to exploit an early morning resource. If, however, foragers cannot adjust the timing of sleep in relation to the timing of work, we predicted that foragers would show the same timing of sleep if they were trained to forage early or late in the day.

\section{METHODS}

\section{Study Site and Subjects}

We transported two small colonies of honeybees (Colony 1: Apis mellifera carnica Pollman, 1879; queen breeder: Strachan Apiaries, Yuba City, CA, U.S.A.; Colony 2: Apis mellifera ligustica Spinola, 1806; queen breeder: C. F. Koehnen and Sons, Glenn, CA, U.S.A.) to Cranberry Lake Biological Station in the Adirondack State Park (NY, U.S.A., $\left.44^{\circ} 09 \mathrm{~N}, 74^{\circ} 48 \mathrm{~W}\right)$. We worked with one colony at a time, installing each one (ca. 2500 bees) in a two-frame observation hive, suspended from the ceiling of a wooden hut (Seeley 1995). Colonies 1 and 2 were set up on 15 July and 9 August 2006, respectively (Fig. 1a).

\section{General Methods}

On the day after setting up each colony, we trained foragers to a feeder filled with a $2.5 \mathrm{M}$ sucrose solution scented with anise. During training and as foragers arrived at the feeder, we marked the foragers with dry pigments mixed in shellac, painting unique colour combinations on the dorsal side of each thorax (mesosoma) and abdomen (metasoma) (Fig. 1b, c). For the next 2 days, we provided food in the feeder only in the early morning (AM training and AM testing days; 0645-0900 hours for Colony 1 and 0645-1000 hours for Colony 2). Beginning at 0600 hours on the AM testing day, B.A.K. recorded each bee's behaviour within the hive every $30 \mathrm{~min}$ for $24 \mathrm{~h}$, scanning both sides of the observation hive in a consistent manner. For 2 days following the AM testing day, we provided food in the feeder only in the late afternoon (PM training and PM testing days; 1600-1900 hours). We blocked the hive entrance with steel screening until 1530 hours on these 2 days to eliminate the risk of losing the AM-trained bees to alternative, natural food sources in the morning. B.A.K. re-examined behaviours of the same individual bees across a second $24 \mathrm{~h}$ period, beginning at 1600 hours on the PM testing day, again examining bees every $30 \mathrm{~min}$ for $24 \mathrm{~h}$ (Fig. 2). The difference in training/testing duration between AM and PM periods in Colony 1 ( $2.25 \mathrm{~h}$ versus $3 \mathrm{~h}$ ) was the result of a trade-off between wishing to achieve maximal temporal separation between AM and PM periods and recording enough activity at the feeder during AM and PM training periods (AM training/testing of Colony 2 lasted an additional hour due to a later onset of activity in the morning relative to Colony 1 ) (Fig. 3). No break was granted between AM testing and PM training days so as to maximize our sample size of foragers by minimizing the number of natural deaths occurring within the time span of the experiment.

For each colony, we trained the foragers to a feeder $18 \mathrm{~m}$ from the wooden hut. We positioned the feeder close to the hive to encourage attendance by our marked bees. To stimulate foraging, we squirted approximately $3 \mathrm{ml}$ of the scented solution into the top of the hive and into the entrance tunnel every day at the beginning of the resource availability period ( 0600 hours or 1600 hours). We used the diffuse light entering the hut through its translucent roof to observe the bees during the day, and we used red-filtered lights to watch them at night. We used red lights at night because bees have low sensitivity to red light (von Frisch 1967; Dustmann \& Geffcken 2000). We defined 'night' as 2200-0600 hours, which roughly corresponded to the time between dusk and dawn. We defined 'morning' and 'afternoon' by the AM training/testing and the PM training/testing periods, above. We did not include a control population of foragers (ones not trained to a feeder, but observed for $24 \mathrm{~h}$ ) because we would not have known when their (natural) food sources would be available, and hence we would not have been able to meaningfully compare their sleep patterns to those of our treatment bees.

\section{Behaviours Recorded}

We recorded 17 distinct behaviours in the hive, and based on our records we determined when each bee was awake or asleep. A bee was awake when she groomed herself or groomed another bee, walked, fanned, turned or lifted her body, performed trophallaxis (exchange of fluid), danced, or was active inside a comb cell (rotated or moved her body rhythmically while deep inside a cell; Sakagami 1953). Less obvious states of wakefulness included relative immobility (defined below) while chewing, being groomed, or an alert stance (body lifted above substrate with antennae extended). Finally, each forager was assumed to be awake when she was outside of the hive. An awake honeybee shows relatively continuous respiratory movements of her metasoma, observable when she is either inside or outside a comb cell. Continuous respiratory movements are contrasted with discontinuous respiration, which typically features pauses of at least $10 \mathrm{~s}$ between respiratory pulses of the metasoma, as revealed by recordings distinguishing heating versus resting bees made by Kleinhenz et al. (2003). We recorded a bee as asleep if she showed relative 

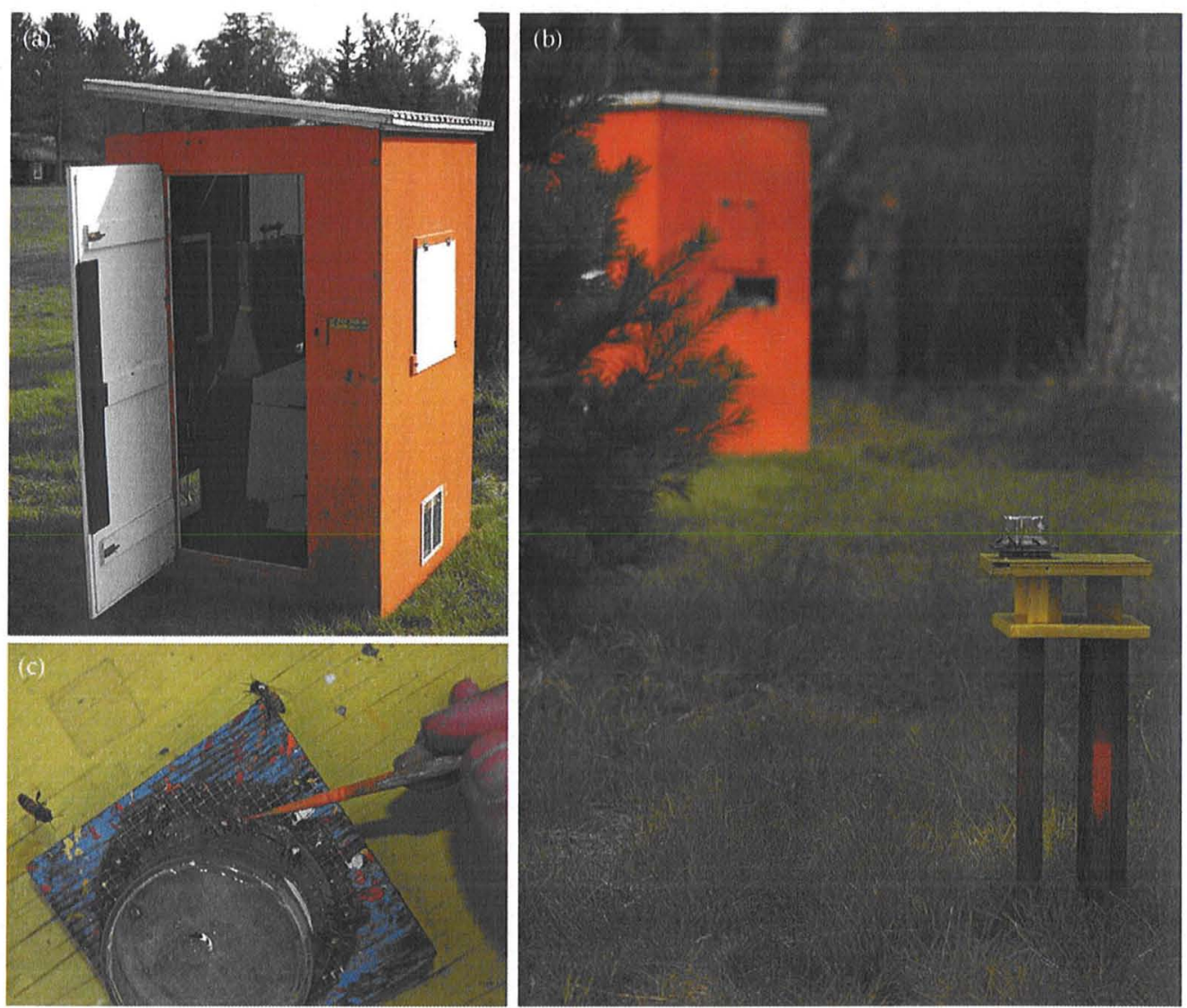

Figure 1. Training and marking of honeybee foragers. The study subjects were (a) housed in an observation hive suspended from the ceiling of a hut, (b) trained to a feeder containing a sucrose solution and (c) individually marked for study.

immobility while discontinuously ventilating, being careful to examine a bee for a minimum of 10 uninterrupted seconds to confirm discontinuous ventilation. For bees outside cells, relative immobility usually takes the form of a bee standing motionless but with occasional twitches of dangling tarsi or legs or, less commonly, extensions of the proboscis. The relative immobility of bees sleeping outside of cells is indistinguishable from that of bees sleeping inside cells (B. A. Klein \& M. K. Busby, unpublished data). For bees sleeping inside a cell, only discontinuous motions of the posterior end of the bee and possible twitching of her hind tarsi are visible. For bees sleeping outside cells, the state of deep sleep (see Introduction) can be recognized in bees showing relative immobility, discontinuous ventilation and immobile antennae.
Confirmation of antennal immobility required an average minimum of $3-5 \mathrm{~s}$ of observation. If a bee was obscured from view, her behavioural state was not recorded. Deep sleep could not be identified in honeybees inside cells.

\section{Statistical Tests}

Our data on the percentage of observations that each forager was seen asleep during each census period were not normally distributed, so we applied the Wilcoxon two-sample test to compare the percentage of observations of AM-trained bees that were asleep during the morning period versus during the afternoon period on the AM testing day, and to compare the percentage of

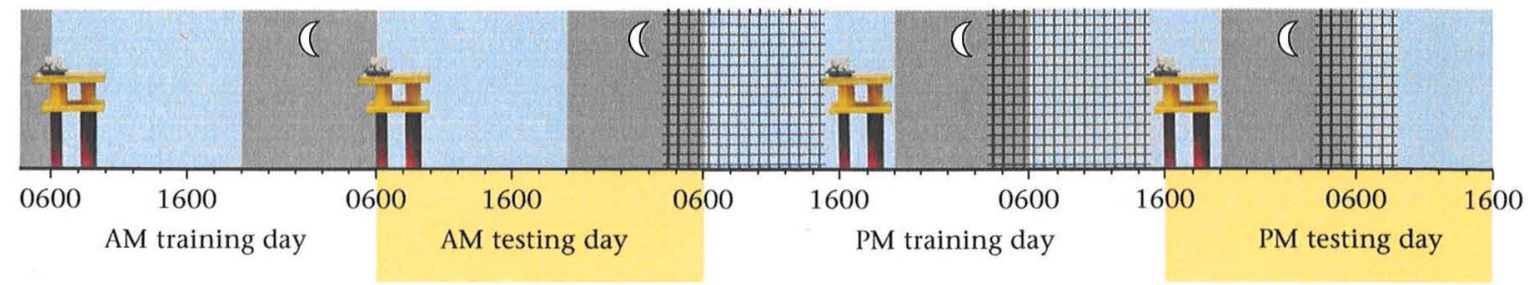

Study timeline

Figure 2. Schedule of training and resource availability. The study timeline begins after 1 day of training foragers to a feeder and individually marking them. Foragers were trained to the feeder during the morning (AM training day) and then monitored inside the hive for $24 \mathrm{~h}$ (AM testing day). Next, the same bees were trained to the feeder during the afternoon (PM training day) and then monitored inside the hive for another $24 \mathrm{~h}$ (PM testing day). A steel screen blocked the entrance on the PM training and PM testing days until 1530 hours to minimize the risk of losing the AM-trained bees to alternative, natural food sources in the morning. Nights are represented by grey areas with crescent moons; the feeder image represents the periods when food was available. 
(a)
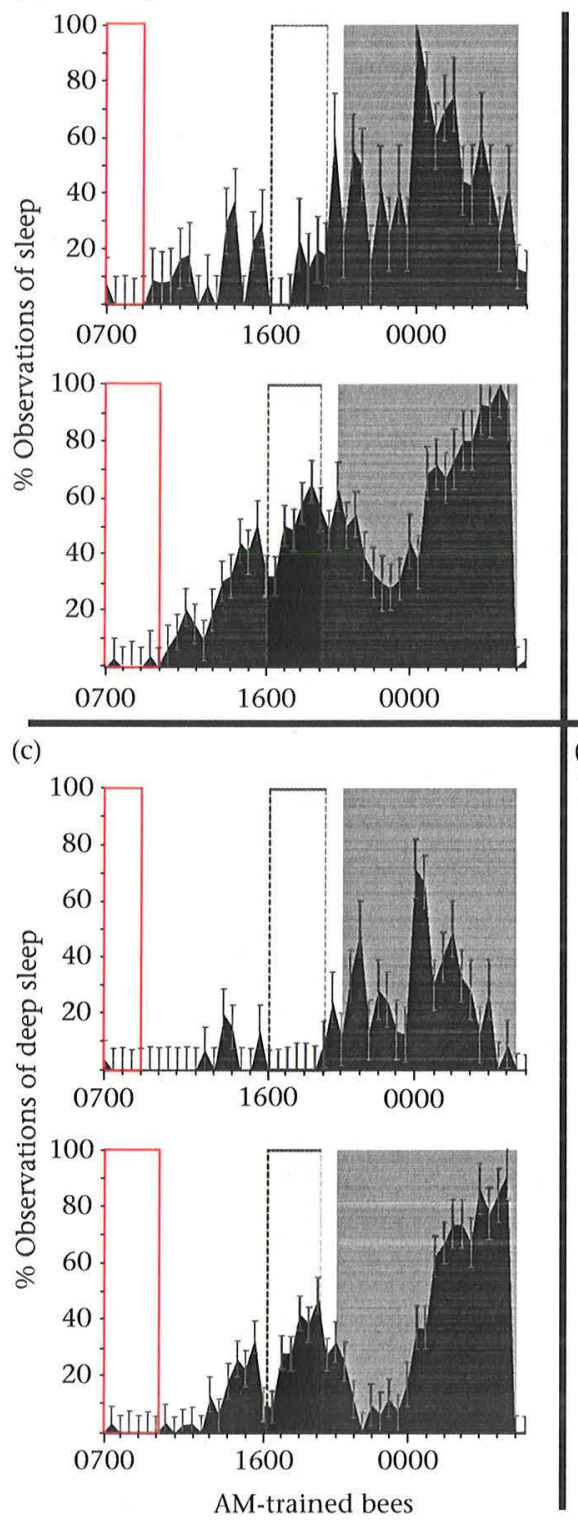

(b)

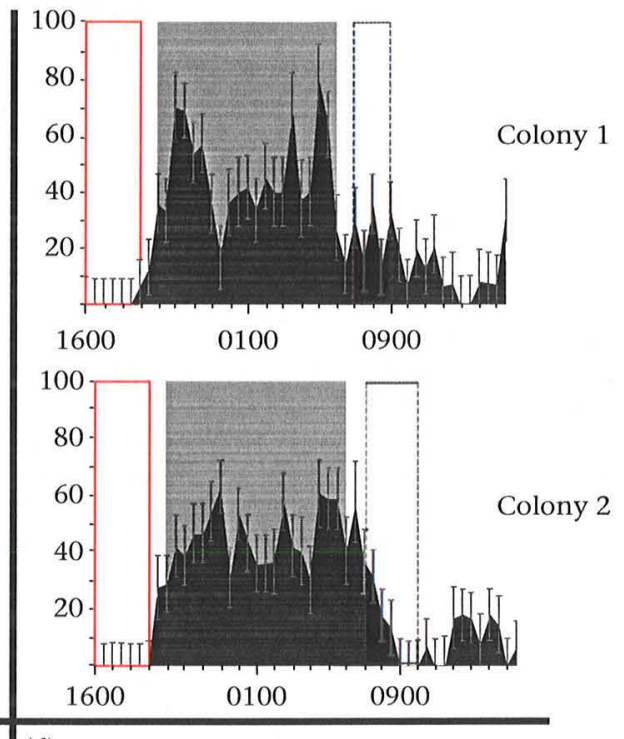

(d)

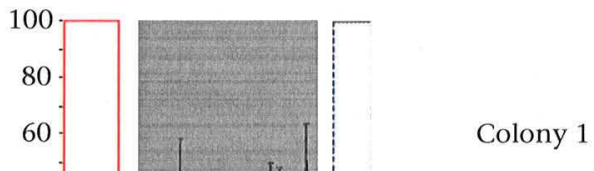

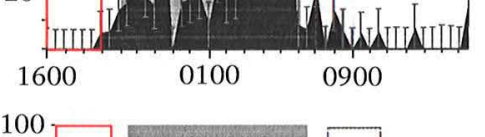

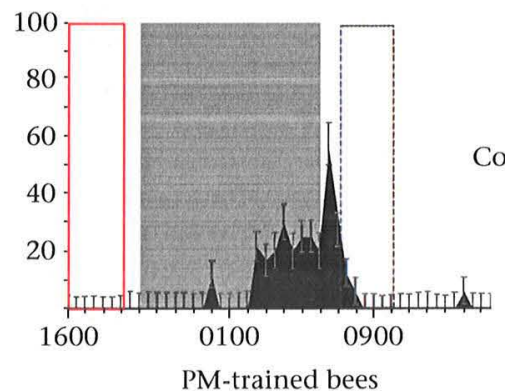

Colony 2

M-trained bees

$24 \mathrm{~h}$ testing periods

Figure 3. Mean percentage of observations that AM- and PM-trained bees were observed (a, b) asleep and, more specifically, in (c, $d$ ) deep sleep, averaged across bees ( $N=16$ bees in Colony 1,21 bees in Colony 2) for each 30 min interval over a $24 \mathrm{~h}$ testing period. Grey backdrop signifies night-time. Boxes with solid outlines: time slot identical to the period during which bees had been previously trained (AM for AM-trained bees, PM for PM-trained bees); boxes with dashed outlines: time slot during the other period of the day (PM for AM-trained bees, AM for PM-trained bees). Width of boxes indicates duration of training/testing periods; differences in training/testing durations result from a trade-off between our desire to achieve maximal temporal separation between AM and PM periods and our ability to record enough activity at the feeder during AM and PM training periods. AM-trained bees from both colonies (a) slept more and (c) showed more deep sleep in the afternoon (boxes with dashed outlines) than in the morning (boxes with solid outlines). Conversely, PM-trained bees from both colonies (b) slept more and (d) showed more deep sleep in the morning (boxes with dashed outlines) than in the afternoon (boxes with solid outlines).

observations of PM-trained bees that were asleep during the afternoon period versus the morning period on the PM testing day. Because we recorded from most of the bees during both the AM and PM periods, we also conducted a Wilcoxon signed-ranks test on the subset of bees that were sampled twice. In addition to comparing the timing of sleep, above, we applied the Wilcoxon two-sample test to compare total observations devoted to individual wakeful and sleep behaviours during the $24 \mathrm{~h}$ AM and PM testing periods. For every test we used the mean value of the percentage observations of sleep per bee per treatment period. Excluded from analyses were bees for which we had behavioural records for three or fewer census periods ( $\leq 6.25 \%$ of 48 census periods, with census periods occurring every $30 \mathrm{~min}$ for $24 \mathrm{~h}$ ). The percentage of unobservable periods did not differ significantly between AM bees and PM bees either in Colony 1 (32.2 $\pm 4.0 \%$ and $21.4 \pm 3.8 \%$ ) or in Colony $2(45.5 \pm 2.5 \%$ and $38.3 \pm 3.5 \%)$. All analyses in the text were performed with the JMP (version 8.0; SAS Institute Inc., Cary, NC, U.S.A.) computer package. Additional analyses in the 


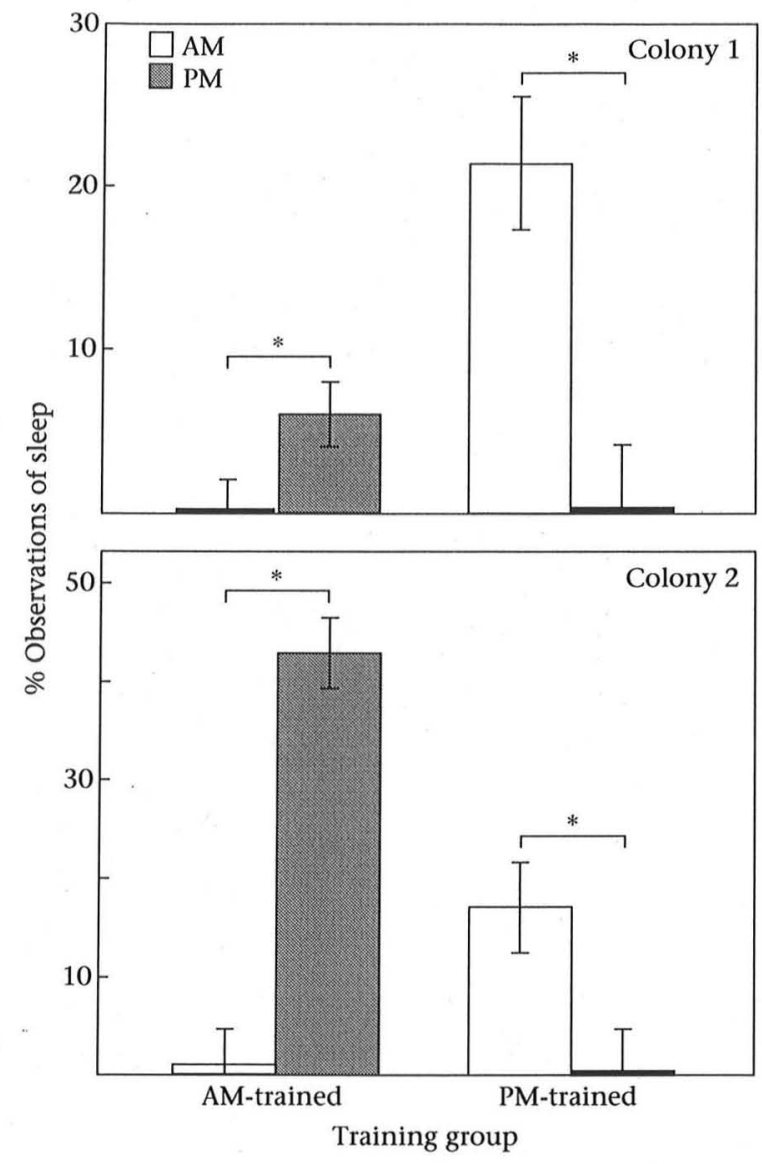

Figure 4. Mean \pm SE percentage of observations in which honeybee foragers were asleep in the morning (AM) or in the afternoon (PM), depending on whether they were recently trained to an early morning food resource (AM-trained, $N=15$ bees in Colony 1,43 bees in Colony 2) or a late afternoon food resource (PM-trained, $N=16$ bees in Colony 1,21 bees in Colony 2). Mean values are based on each bee's average value for the AM or PM period, corresponding to the boxes in Fig. 3. ${ }^{*} P<0.05$.

Supplementary Material were coded in R ( R Development Core Team 2005). We report summary statistics of continuous variables as means $\pm \mathrm{SE}$. We set alpha at 0.05 for all tests, and all tests were two tailed.

\section{RESULTS}

\section{Timing of Resource Availability and Daytime Sleep}

Foragers trained to a feeder in the morning or in the afternoon showed different patterns of daytime sleeping, including deep sleep (Fig. 3). Foragers trained to a feeder in the morning slept more during the afternoon period than during the morning period of the AM testing day (Wilcoxon two-sample test: Colony $1: Z=2.07$, $N=15$ bees, $P=0.0384$; Colony $2: Z=6.85, N=46$ AM bees and 45 PM bees, $P<0.0001$; Figs 3a, 4). Likewise, foragers trained to a feeder in the afternoon subsequently slept more during the morning period than during the afternoon period of the PM testing day (Wilcoxon two-sample test: Colony $1: Z=3.49, N=16$ AM bees and 17 PM bees, $P=0.0005$; Colony $2: Z=2.63, N=22$ AM bees and 23 PM bees, $P=0.0085$; Figs $3 \mathrm{~b}, 4$ ). All results above were confirmed using a Wilcoxon signed-ranks test (after excluding data for foragers only recorded during either AM or PM periods so that each bee could be paired with herself) except for AM testing in

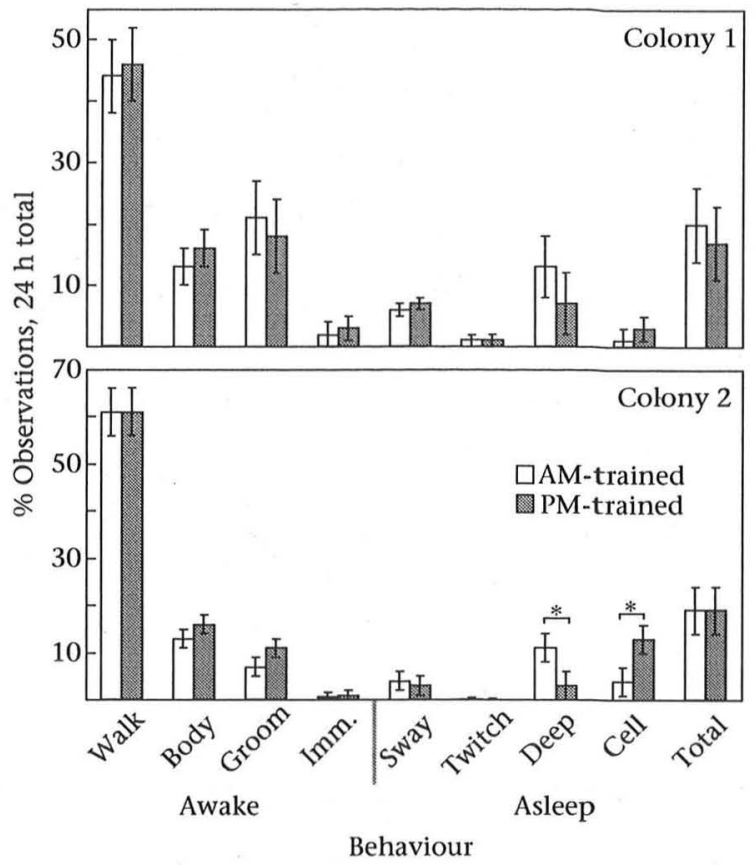

Figure 5. Mean $\pm S E$ percentage of observations of primary behaviours of AM- and PM-trained bees in Colony $1(N=9)$ and Colony $2(N=18)$ across 24 h periods. Bees generally performed similar amounts of each behaviour, irrespective of when they were trained to a food source (exceptions are noted with asterisks). Walk: locomotion; Body: body movement; Groom: grooming; Imm.: relatively immobile; Sway: swaying antenna(e); Twitch: twitching antenna(e); Deep: deep sleep (with immobile antennae): Cell: inside cell; Total: sum of all observations while asleep.

Colony 1 (AM testing: Colony 1: $T=5.00, N=15$ bees, $P=0.1250$; Colony 2: $T=274.50, N=43$ bees, $P<0.0001$; PM testing: Colony 1: $T=-22.50, N=16$ bees, $P=0.0039$; Colony $2: T=-10.50$, $N=21$ bees, $P=0.0313$ ). For further confirmation of these results using a chi-square test, and for a simulation further indicating that these results were not due to repeated measures on the same bee, see Supplementary Material.

\section{Total Time Devoted to Behaviours}

Time devoted to sleep and nonsleep behaviours over a $24 \mathrm{~h}$ period generally did not differ between bees that foraged in the early morning versus in the late afternoon (Fig. 5). The only exceptions to this were deep sleep and sleep inside cells for Colony 2, but even here the sums of these two sleep measures were statistically indistinguishable between the two testing days. Total time spent sleeping at night also did not differ between AM- and PM-trained bees $(45.2 \pm 5.9 \%$ and $44.5 \pm 5.5 \%$ of observations in Colony $1 ; 49.5 \pm 4.7 \%$ and $40.3 \pm 6.0 \%$ of observations in Colony 2 ), although PM-trained bees slept more inside cells during the night than AM-trained bees (Wilcoxon two-sample test: Colony 1: $Z=-2.63, N=17$ and 14 bees, $P=0.0086$; Colony $2: Z=3.40$, $N=24$ and 46 bees, $P=0.0007$ ). Of the total observations asleep during morning and afternoon periods, approximately half were devoted to deep sleep and a small percentage to sleep inside cells (see Supplementary Material).

\section{DISCUSSION}

The two most intriguing findings of this study are that honeybee foragers can engage in considerable sleep during the day, and that 
they adjust the timing of their daytime sleep in relation to the timing of available forage. Previous studies of honeybee sleep have invariably studied forager sleep as primarily a night-time phenomenon (Kaiser 1988; Sauer et al. 2003; Eban-Rothschild \& Bloch 2008; Klein et al. 2008), but it is now clear that this is not the full story. Karl von Frisch made the general observation that foragers 'doze undisturbed' (von Frisch 1967, page 255) during the day when not foraging and that they form a 'verschlafene Gesellschaft' (sleeping society) between harvesting times (von Frisch 1940). Also, Klein et al. (2008) reported that foragers sleep $13-17 \%$ of the time during the day and $36-56 \%$ of the time during the night. The present study builds on these previous reports by rigorously confirming the phenomenon of daytime sleep and by showing how it is timed in relation to a forager's work schedule. The foragers that we observed showed virtually no sleep when forage was available, but did sleep off and on throughout the rest of the day (Fig. 3). Evidently, the timing of daytime sleep by foragers is determined at least in part by one specific extrinsic factor: when forage is available. It remains unknown, however, how foragers sense when there is a lack of available forage, hence when they can go to sleep. In this regard, it would be interesting to closely observe foragers trained to a feeder that provides food for just a few hours each day and see how they switch from working to sleeping and, eventually, from sleeping back to working.

Also unknown is the function of this seemingly opportunistic, daytime sleep. Sleep may serve as a default noninterference behaviour for foragers during the day and may provide no extra benefits. Siegel (2009) proposed that sleep may serve to increase a behaviour's efficiency by regulating its timing and by reducing energy expenditure. Sleep decreases one's metabolic rate and has long been functionally linked with energy conservation (Berger \& Phillips 1995). Honeybee foragers showing small or no movements have lower metabolic rates than more active bees in the hive (Stabentheiner et al. 2003) and daytime sleep may provide a means of minimizing the costs of foraging, by lowering a forager's energy expenditure when there is no forage to collect. Another possible function of daytime sleep in foragers is that it serves to maximize the benefits of foraging, perhaps by helping the bees consolidate their memories of the location, odour and other traits of the flowers that they have recently exploited. Sleep promotes consolidation of memories in mammals (Walker \& Stickgold 2006; Diekelmann \& Born 2010), and sleep in the fruit fly, Drosophila (Sophophora) melanogaster, may be regulated by its learning and memory brain centres (Pitman et al. 2006), so it is quite possible that honeybees benefit from sleep-promoting memory consolidation in a manner similar to that experienced by other animals.

The present study demonstrates that honeybee foragers can modify the timing of their sleep during the day in response to a change in the timing of profitable work. This is analogous to the way that humans employed in some organizations must shift their sleep schedules to accommodate shifts in their work schedules. Shift work in humans can result in a wide array of health and performance problems, and naps show evidence of improving alertness and performance (Lovato et al. 2009). Is daytime sleep by honeybee foragers a means of coping with adverse effects of shift work? By examining how honeybees perform when challenged by more extreme shift work schedules analogous to those experienced by some humans, it may be possible to assess costs associated with shift work in honeybees. It is already known that Apis mellifera adansonii (reviewed by Fletcher 1978) and A. dorsata (Dyer 1985) forage on moonlit nights, and that Africanized and European honeybees actively defend their nests at night (Eischen et al. 1986). Do such actions constitute shift work, and are there similarities across social species in how individuals cope with changing work schedules by changing their sleep schedules? The study of honeybee foragers offers opportunities to investigate the costs and benefits of shift work in nonhuman societies.

\section{Acknowledgments}

Margaret Wray was instrumental in helping record visits to the feeder and with other aspects of the field work. Alex Weir and Lawrence Rathman hosted and facilitated our research at Cranberry Lake Biological Station. Samuel Scarpino graciously contributed statistics guidance. Arno Klein and two anonymous referees provided helpful comments. Texas EcoLab, and the University of Texas at Austin's Program of Ecology, Evolution \& Behavior provided funding, and we thank our honeybees.

\section{Supplementary Material}

Supplementary material associated with this article is available, in the online version, at doi:10.1016/j.anbehav.2011.03.026.

\section{References}

Arendt, J. 2010. Shift work: coping with the biological clock. Occupational Medicine- $C$ 60, $10-20$.

Basner, M., Rubinstein, J., Fomberstein, K. M., Coble, M. C., Ecker, A., Avinash, D. \& Dinges, D. F. 2008. Effects of night work, sleep loss and time on task on simulated threat detection performance. Sleep, 31, 1251-1259.

Beling, I. 1929. Öber das Zeitgedächtnis der Bienen. Zeitschrift für vergleichende Physiologie, 9, 259-338.

Berger, R. J. \& Phillips, N. H. 1995. Energy conservation and sleep. Behavioural Brain Research, 69, 65-73.

Costa, G. 1996. The impact of shift and night work on health. Applied Ergonomics, 27, 9-16.

Dhand, R. \& Sohal, H. 2006. Good sleep, bad sleep! The role of daytime naps in healthy adults. Sleep and Respiratory Neurobiology, 12, 379-382.

Diekelmann, S. \& Born, J. 2010. The memory function of sleep. Nature, 11, 114-126. Dustmann, J. H. \& Geffcken, H. 2000. Bienen können Farben unterscheiden Niedersächsisches Landesinstitut für Bienenkunde (Verleger), Celle, 13, 1-3.

Eban-Rothschild, A. D. \& Bloch, G. 2008. Differences in the sleep architecture of forager and young honeybees (Apis mellifera). Journal of Experimental Biology, 211, 2408-2416.

Dyer, F. C. 1985 . Nocturnal orientation by the Asian honey bee, Apis dorsata. Animal Behaviour, 33, 769-774.

Eischen, F. A., Rinderer, T. E. \& Dietz, A. 1986. Nocturnal defensive responses of Africanized and European honey bees to the greater wax moth (Galleria mellonella L.). Animal Behaviour, 34, 1070-1077.

Flanigan, W. F., Wilcox, R. H. \& Rechtschaffen, A. 1973. The EEG and behavioral continuum of the crocodilian, Caiman sclerops. Electroencephalography and Clinical Neurophysiology, 34, 521-538.

Fletcher, D. J. C. 1978. The African bee, Apis mellifera adansonii, in Africa. Annua Review of Entomology, 23, 151-171.

von Frisch, K. 1940. Die Tänze und das Zeitgedächtnis der Bienen im Widerspruch. Naturwissenschaften, 28, 65-69.

von Frisch, K. 1967. The Dance Language and Orientation of Bees. Cambridge, Massachusetts: Belknap Press.

Garbarino, S., Beelke, M., Costa, G., Violani, C., Lucidi, F., Ferrillo, F. \& Sannita, W. G. 2002. Brain function and effects of shift work: implications for clinical neuropharmacology. Neuropsychology, 45, 50-56.

Hendricks, J. C., Finn, S. M., Panckeri, K. A., Chavkin, J., Williams, J. A., Sehgal, A. 8 Pack, A. I. 2000. Rest in Drosophila is a sleep-like state. Neuron, 25, 129-138.

Hussaini, S. A., Bogusch, L., Landgraf, T. \& Menzel, R. 2009. Sleep deprivation affects extinction but not acquisition memory in honeybees. Learning $\mathcal{E}$ Memory, 16, 698-705.

Kaiser, W. 1988. Busy bees need rest, too: behavioural and electromyographical sleep signs in honeybees. Journal of Comparative Physiology A, 163, 565-584.

Kaiser, W. \& Steiner-Kaiser, J. 1983. Neuronal correlates of sleep, wakefulness, and arousal in a diurnal insect. Nature, 301, 707-709.

Kaiser, W., Weber, T. \& Otto, D. 1996. Vegetative physiology at night in honey bees. In: Proceedings of the 24th Göttingen Neurobiology Conference. Vol. 2 (Ed. by N. Elsner \& H.-U. Schnitzler). Stuttgart: Thieme Verlag page 140.

Klein, B. A. 2003. Signatures of sleep in a paper wasp. Sleep, 26. A115-A116.

Klein, B. A., Olzsowy, K. M., Klein, A., Saunders, K. M. \& Seeley, T. D. 2008. Castedependent sleep of worker honey bees. Journal of Experimental Biology, 211 3028-3040.

Klein, B. A., Klein, A., Wray, M. K., Mueller, U. G. \& Seeley, T. D. 2010. Sleep deprivation impairs precision of waggle dance signaling in honey bees. Proceedings of the National Academy of Sciences, U.S.A., 107, 22705-22709.

Kleinhenz, M., Bujok, B., Fuchs, S. \& Tautz, J. 2003. Hot bees in empty broodnest cells: heating from within. Journal of Experimental Biology, 206, 4217-4231. 
Koltermann, R. 1971. 24-Std-Periodik in der Langzeiterinnerung an Duft- und Farbsignale bei der Honigbiene. Zeitschrift für vergleichende Physiologie, 75, $49-68$.

Körner, I. 1939. Zeitgedächtnis und Alarmierung bei den Bienen. Zeitschrift für vergleichende Physiologie, 27, 445-459.

Lindauer, M. 1952. Ein Beitrag zur Frage der Arbeitsteilung im Bienenstaat. Zeitschrift für vergleichende Physiologie, 34, 299-345.

Lovato, N., Lack, L., Ferguson, S. \& Tremaine, R. 2009. The effects of a 30-min nap during night shift following a prophylactic sleep in the afternoon. Sleep and Biological Rhythms, 7, 34-42.

Moore, D. 2001. Honey bee circadian clocks: behavioral control from individua workers to whole-colony rhythms. Journal of Insect Physiology, 47, 843-857.

Moore, D. \& Rankin, M. A. 1983. Diurnal changes in the accuracy of the honeybee foraging rhythm. Biological Bulletin, 164, 471-482.

Moore, D., Siegfried, D., Wilson, R. \& Rankin, M. A. 1989. The influence of time of day on the foraging behavior of the honeybee, Apis mellifera. Journal of Biological Rhythms, 4, 305-325.

Moore, D., Angel, J. E., Cheeseman, I. M., Farhbach, S. E. \& Robinson, G. E. 1998 Timekeeping in the honey bee colony: integration of circadian rhythms and division of labor. Behavioral Ecology and Sociobiology, 43, 147-160.

Piéron, H. 1913. Le Problème Physiologique du Sommeil. Paris: Masson.

Pitman, J. L., McGill, J. J., Keegan, K. P. \& Allada, R. 2006. A dynamic role for the mushroom bodies in promoting sleep in Drosophila. Nature, 441, 753-756.

R Development Core Team 2005. A Language and Environment for Statistical Computing. Vienna, Austria: R Foundation for Statistical Computing (ISBN 3-900051-07-0, online).

Rajaratnam, S. M. W. \& Arendt, J. 2001. Health in a 24-h society. Lancet, 358, 999-1005.

Sakagami, S. F. 1953. Untersuchungen über die Arbeitsteilung in einem Zwergvolk der Honigbiene. Beiträge zur Biologie des Bienenvolkes, Apis mellifera L. I. Japanese Journal of Zoology, 11, 117-185

Sauer, S., Kinkelin, M., Herrmann, E. \& Kaiser, W. 2003. The dynamics of sleeplike behaviour in honey bees. Journal of Comparative Physiology A, 189, 599-607.
Sauer, S., Herrmann, E. \& Kaiser, W. 2004. Sleep deprivation in honey bees. Journal of Sleep Research, 13, 145-152.

Seeley, T. D. 1995. The Wisdom of the Hive: the Social Physiology of Honey Bee Colonies. Cambridge, Massachusetts: Harvard University Press.

Siegel, J. M. 2009. Sleep viewed as a state of adaptive inactivity. Nature Reviews Neuroscience, 10, 747-753.

Shaw, P. J., Cirelli, C., Greenspan, R. J. \& Tononi, G. 2000. Correlates of sleep and waking in Drosophila melanogaster. Science, 287, 1834-1837.

Smith-Coggins, R., Howard, S. K., Mac, D. T., Wang, C., Kwan, S., Rosekind, M. R., Sowb, Y., Balise, R., Levis, J. \& Gaba, D. M. 2006. Improving alertness and performance in emergency department physicians and nurses: the use of planned naps. Annals of Emergency Medicine, 48, 596-604.e2.

Spangler, H. 1972. Daily activity rhythms of individual worker and drone honey bees. Annals of the Entomological Society of America, 65, 1073-1076.

Stabentheiner, I., Vollmann, J., Kovac, H. \& Crailsheim, K. 2003. Oxygen consumption and body temperature of active and resting honeybees. Journal of Insect Physiology, 49, 881-889.

Tobler, I. 1983. Effect of forced locomotion on the rest-activity cycle of the cockroach. Behavioural Brain Research, 8, 351-360.

Tobler, I. 1985. Deprivation of sleep and rest in vertebrates and invertebrates. In: Endogenous Sleep Substances and Sleep Regulation. Series No. 8, Taniguchi Symposia (Ed. by S. Inoue \& A. A. Borbely), pp. 57-66. Utrecht: VNU Science Press.

Tobler, I. \& Neuner-Jehle, M. 1992. 24-h variation of vigilance in the cockroach Blaberus giganteus. Journal of Sleep Research, 1, 231-239.

Toma, D. P., Bloch, G., Moore, D. \& Robinson, G. E. 2000. Changes in period mRNA levels in the brain and division of labor in honey bee colonies. Proceedings of the National Academy of Sciences, U.S.A., 97, 6914-6919.

Wahl, 0. 1932. Neue Untersuchungen über das Zeitgedächtnis der Bienen. Zeitschrift für vergleichende Physiologie, 16, 529-589.

Wahl, O. 1933. Beitrag zur Frage der biologischen Bedeutung des Zeitgedächtnisses der Bienen. Zeitschrift für vergleichende Physiologie, 16, 709-717.

Walker, M. P. \& Stickgold, R. 2006. Sleep, memory, and plasticity. Annual Review of Psychology, 57, 139-166. 